\title{
Position Control of Electro-hydraulic Actuator System Using Fuzzy Logic Controller Optimized by Particle Swarm Optimization
}

\author{
Daniel M. Wonohadidjojo ${ }^{1} \quad$ Ganesh Kothapalli $^{1} \quad$ Mohammed Y. Hassan $^{2}$ \\ ${ }^{1}$ School of Engineering, Edith Cowan University, Western Australia 6027, Australia \\ ${ }^{2}$ University of Technology, Baghdad, Iraq (Adjunct Academic, Edith Cowan University, Western Australia 6027, Australia)
}

\begin{abstract}
The position control system of an electro-hydraulic actuator system (EHAS) is investigated in this paper. The EHAS is developed by taking into consideration the nonlinearities of the system: the friction and the internal leakage. A variable load that simulates a realistic load in robotic excavator is taken as the trajectory reference. A method of control strategy that is implemented by employing a fuzzy logic controller (FLC) whose parameters are optimized using particle swarm optimization (PSO) is proposed. The scaling factors of the fuzzy inference system are tuned to obtain the optimal values which yield the best system performance. The simulation results show that the FLC is able to track the trajectory reference accurately for a range of values of orifice opening. Beyond that range, the orifice opening may introduce chattering, which the FLC alone is not sufficient to overcome. The PSO optimized FLC can reduce the chattering significantly. This result justifies the implementation of the proposed method in position control of EHAS.
\end{abstract}

Keywords: Position control, electro-hydraulic actuator, fuzzy logic controller, particle swarm optimization (PSO), nonlinear.

\section{Introduction}

Position control applications in most equipment that are implemented using servo mechanism need a robust control scheme with tracking accuracy. This requires good positioning and smooth response of the actuation system. Due to their capability, electro-hydraulic actuators have been used in these servo systems for the last few years. Its robustness and accuracy of position tracking contribute significantly to the applications and equipment such as robotics, mining, and aircraft.

The constraints appearing in the applications of the hydraulic control system are the internal and external disturbances that yield the nonlinearities and uncertainties. Such characteristics emerge on the system and degrade its performance significantly. These disturbances have adverse impact on the robustness and accuracy of position tracking of the system. Such nonlinearities and uncertainties in the hydraulic actuation system are caused by the presence of friction and internal leakage of the system.

The performance of electro-hydraulic actuator system (EHAS) in position control requires an accurate electrohydraulic actuator which is determined by its position tracking performance and robustness of the controller. Therefore, the development of such system which guarantees the tracking accuracy and robustness is significant.

Nonlinearities and uncertainties in EHAS arise from the friction and internal fluid leakage in the system. A large number of studies have been conducted to overcome these problems, in which friction has received more attention. Despite the less number of studies on the leakage, it cannot be neglected in practices. Both friction and leakage effects introduce chattering which degrades the performance of the system in terms of tracking performance and robustness.

Manuscript received May 25, 2012; revised December 3, 2012
A number of studies have been conducted to minimize the impact of friction and internal leakage. Issues related to the control of the electro-hydraulic actuators was addressed ${ }^{[1]}$, in which a nonlinear model of hydraulic cylinder controlled by servo valves was developed. Specifically, a linearized model of a hydraulic servo system was used to develop a proportional, integral and derivative (PID) controller. It also utilized the design of feedback linearization controller to overcome some limitations of the linear controllers. This led to the improved performance of feedback linearization control compared to the PID control. A similar study proposing a technique that combined the features of sliding mode control and fuzzy control was reported ${ }^{[2]}$. However, the systems developed in both of these studies still suffered from chattering. The fuzzy logic was only employed to accelerate the phase change and attenuate the chattering introduced by the sliding mode control method. In addition, the study did not take into account the internal fluid leakage in the hydraulic system.

In [3], a technique was proposed for the control of excavator dynamics and its hydraulic actuators when executing robotic excavation tasks involving soil contact operations. The results obtained suggested that the proposed control technique can provide robust performance when employed in the automated excavation with soil contact. However, the robustness of this system to the chattering in the hydraulic actuator was not addressed in this study. The fuzzy tuning approach implemented for the control of the ram force and the cylinder position did not specify the friction and internal leakage of the excavator hydraulic actuator system, either.

A self-tuning fuzzy PID controller, developed to improve the performance of the electro-hydraulic actuator ${ }^{[4]}$, was based on the mathematical model of the system. This method used a system identification technique and fuzzy 
logic to tune each parameter of the PID controller. However, this study did not consider the load of the hydraulic system, the friction in the hydraulic cylinder and the leakage in the hydraulic actuator system. Another study which described an application of a fuzzy logic position control to an electro-hydraulic servo system ${ }^{[5]}$ included a mathematical model of that system which considered its internal leakage. However, this work did not take into account the load of the electro-hydraulic system.

An adaptive control scheme was reported in [6] to overcome system uncertainty. This approach used the error equations for velocity, acceleration and jerk, which were generated in the design procedure of the standard backstepping control scheme. However, a major issue concerning the load of the actuator system was not addressed.

In [7], a fuzzy plus proportional integral (PI) controller, which combined fuzzy logic and conventional PI control was developed with a fuzzy rule based on the soft-switch method. This study did not address specific nonlinearity and uncertainty parameters in the electro-hydraulic system. Furthermore, the switching mechanism used was not tested using these parameters to verify its robustness and smooth switching.

In another study, retrofitted electro-hydraulic pilot proportional relief valves were developed to effect an excavator automatization $^{[8]}$. This study also developed a model of excavator motion control. The system was used to handle the nonlinearity, parameter uncertainties and external disturbances. However, questions were raised over the system's robustness, because the study did not specify the nonlinearities and parameter uncertainties that emerged in the system.

A sliding mode control (SMC) with fixed and varying boundary layers was proposed ${ }^{[9]}$. The controller scheme was employed to control the position tracking performance of an electro-hydraulic actuator system. It was aimed to compensate for nonlinearities and uncertainties caused by the presence of friction and internal leakage, and this study also considered a fixed load for the system. However, the chattering in the SMC's control signals, due to the discontinuous term in its control law, was not overcome.

An available nonlinear observer for Coulomb friction was modified to simultaneously estimate friction, velocity, and acceleration. This scheme was investigated in [10]. An observer-based friction compensating control strategy was developed to improve tracking performance of the manipulator. This study did not take into consideration the leakage that emerged in the electro-hydraulic system.

In this paper, a method to control the position of electrohydraulic servo system is proposed. The objective of this study is to develop a method of position control of the EHAS using an intelligent controller. The controller is robust to the nonlinearities and uncertainties that emerge in the system. The position tracking should be able to find the optimum parameters of the controller so that the error in position and chattering are minimized. The development of that method includes several steps. First, a fuzzy logic controller (FLC) is designed as the controller of the nonlinear model of electro-hydraulic system. The model takes into consideration the friction and internal leakage. Then, the unoptimized FLC is employed and the system response is observed with computer simulation. Next, parameters of the FLC are optimized by the particle swarm optimization (PSO) algorithm. The optimized parameters are the scaling factors of the fuzzy inference system. When the optimized parameters are obtained, the performance and robustness of the unoptimized and optimized FLC is compared. The optimization is confirmed through computer simulation.

Despite the wide range of applications of EHAS in industries, aircraft, robotics and machinery, it will be investigated by taking into consideration the use of EHAS in excavators in this paper.

The paper is organized as follows. Section 2 describes the mathematical models to develop the electro-hydraulic servo system with the complete Simulink model presented at the end of this section. The FLC design is explained in Section 3. Then, we explain the PSO in Section 4. The testing and simulations of the position control of the electro-hydraulic actuator system are presented in Section 5 followed by the results and discussion in Section 6. We then conclude our study in Section 7.

\section{Electro-hydraulic actuator system}

\subsection{Hydraulic dynamics and force balance model}

The electro-hydraulic actuator system modelled in this study consists of two main parts: the valve and the cylinder. The cylinder is modelled as a double acting single rod or single ended piston, with a single load attached at the end of the piston. The cylinder is depicted in Fig. $1^{[11]}$.

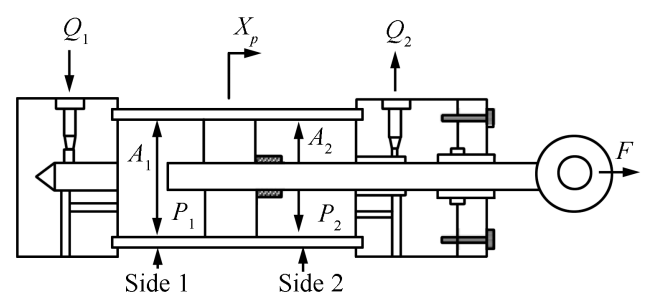

Fig. 1 Electro-hydraulic cylinder

In Fig. $1, X_{p}$ is the cylinder position, $F$ denotes the applied load to the cylinder, $Q_{1}$ and $Q_{2}$ are the fluid flow to and from the cylinder, respectively. $P_{1}$ is the fluid pressure within side 1 and $P_{2}$ is the fluid pressure within side 2. The pressurized areas on side 1 and side 2 are $A_{1}$ and $A_{2}$, respectively. The cylinder will retract or extend when a pressure difference between $P_{1}$ and $P_{2}$ occurs.

The dynamics of the system is expressed by

$$
\begin{aligned}
& \dot{X}_{p}=V_{p} \\
& m a_{p}=F_{a}-F_{f}
\end{aligned}
$$

where $X_{p}$ is the piston position, $V_{p}$ is the piston velocity, $a_{p}$ is the piston acceleration, and $m$ is the piston and load mass. There are two forces in (2) that influence the system: the hydraulic actuating force $F_{a}$ and the friction force $F_{f}$ which are functions of nonlinearities that will significantly influence the system. The parameters that affect $F_{a}$ are the control input voltage, environment load, cylinder pressure, 
friction force and leakage. Hence, it can be represented by

$$
F_{a}=A_{p} P_{l} .
$$

Therefore, the force balance equality of the cylinder is represented by

$$
m a_{p}=A_{p} P_{l}-F_{f}
$$

where $A_{p}$ is the cross section of the hydraulic cylinder, and $P_{l}$ is the cylinder differential pressure written as

$$
P_{l}=P_{1}-P_{2} .
$$

Equality (4) represents the dynamics of the system.

As discussed in [9], by defining the load pressure $P_{l}$ to be the pressure across the actuator piston, the derivative of the load pressure is given by the total load flow through the actuator divided by the fluid capacitance as

$$
\frac{V_{t}}{\beta_{e}} \dot{P}_{l}=Q_{l}-C_{t} P_{l}-A_{p} V_{p}
$$

where $V_{t}$ is the total actuator volume of both cylinder sides, $\beta_{e}$ is the bulk modulus of hydraulic oil, $C_{t}$ is the total leakage coefficient, and $Q_{l}$ is the load flow. By using (6), the flow equality of the servo valve is given in (7), which expresses the relationship between spool valve displacement $X_{v}$ and the load flow $Q_{l}$.

$$
Q_{L}=C_{d} w x_{v} \sqrt{\frac{p_{s}-\operatorname{sgn}\left(x_{v}\right) p_{l}}{\rho}}
$$

where $C_{d}$ is discharge coefficient, $W$ is the spool valve area gradient, $P_{s}$ is the supply pressure, and $\rho$ is the oil density. Substituting (7) into (6), one can find the hydraulics dynamics of the cylinder pressure as

$$
\dot{P}_{l}=\frac{4 \beta_{e}}{V_{t}}\left[-A_{p} v_{p}-c_{t} p_{l}+C_{d} w x_{v} \sqrt{\frac{P_{s}-\operatorname{sgn}\left(x_{v}\right) p_{l}}{\rho}}\right] .
$$

The spool displacement of the servo valve $X_{v}$ is controlled by the control signal generated by the FLC $u$. The corresponding relation can be simplified to

$$
\dot{X}_{v}=\frac{1}{\tau_{v}}\left(-x_{v}+k_{v} u\right) \text {. }
$$

The servo valve input can also be expressed as a second order equation as

$$
U=\frac{1}{k_{v}}\left(\frac{1}{\omega_{v}^{2}} \ddot{x}_{v}+\frac{2 D R_{v}}{\omega_{v}} \dot{x}_{v}+x_{v}\right)
$$

where $k_{v}$ is the servo valve gain, $\tau_{v}$ is the time constant, $\omega_{v}$ is the natural frequency, and $D R_{V}$ is the damping ratio of servo valve. Based on (1)-(10), if the state variables are determined as

$$
x=\left[x_{1}, x_{2}, x_{3}\right]^{\mathrm{T}}=\left[x_{p}, v_{p}, a_{p}\right]^{\mathrm{T}}
$$

then a third order state equation model for the servo hydraulic actuator system can be obtained by replacing the valve dynamics (9) with

$$
x_{v}=k_{v} u .
$$

Then, the following equalites can be obtained as

$$
\begin{aligned}
\dot{x}_{1} & =x_{2} \\
\dot{x}_{2} & =x_{3} \\
\dot{X}_{3} & =\dot{a}_{p}=\frac{1}{m}\left(A_{p} \dot{p}_{l}-\dot{F}_{f}\right) .
\end{aligned}
$$

\subsection{Friction model}

Friction is an important aspect of many control systems both for high quality servo mechanisms and simple pneumatic and hydraulic systems. Friction can lead to tracking errors, limit cycles, and undesired stick-slip motion ${ }^{[12]}$. Friction is the tangential reaction force between two surfaces in contact. Physically, these reaction forces are the results of many different mechanisms, which depend on contact geometry and topology, properties of the bulk and surface materials of the bodies, displacement and relative velocity of the bodies, and presence of lubrication ${ }^{[6]}$.

The commonly used model for friction is usually depicted by the discontinuous static mapping between velocity and friction force. This needs to consider the Coulomb and viscous friction that depends on the velocity sign. The static model, however, does not take into consideration the dynamics behavior of the friction force, such as stick-slip motion, re-sliding displacement and friction lag. These characteristics are properties of friction in nature. Therefore, friction does not have instantaneous response to the velocity change.

In order to model the static and dynamic behavior of friction force, LuGre model ${ }^{[13]}$ is used in the design of friction in this study. It accommodates both the static and dynamic characteristics of the friction force. Fig. 2 shows the characteristic of friction-velocity of this model. The friction characteristics are generated during two cycles of oscillation. The oscillation results in a narrow hysteretic effect around the zero relative velocity in the graph (presliding motion area $)^{[14]}$.

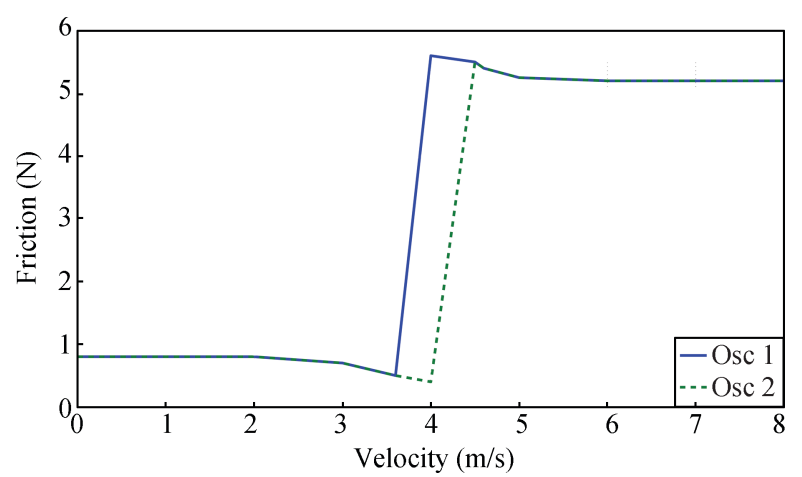

Fig. 2 Characteristic of friction force-velocity ${ }^{[9]}$

LuGre model is expressed by ${ }^{[4]}$

$$
\begin{aligned}
& F_{f}=\sigma_{0} z+\sigma_{1} \dot{z}+\sigma_{2} v_{p} \\
& \dot{z}=v_{p}-\frac{\left|v_{p}\right|}{g\left(v_{p}\right)} z
\end{aligned}
$$

where $z$ is the average deflections of the bristle between each pair of the contact surfaces described by the friction internal state, $v_{p}$ is the relative velocity between two sur- 
faces $\sigma_{0}, \sigma_{1}$, and $\sigma_{2}$ are the stiffness of the bristle between two contact surfaces, the bristles damping coefficient, and the viscous friction coefficient, respectively. The nonlinear property of friction is described by $g\left(v_{p}\right)$ in (18), which can be parameterized to characterize the Stribeck effect.

$$
g\left(v_{p}\right)=\frac{1}{\sigma_{0}}\left[F_{c}+\left(F_{s}-F_{c}\right) \mathrm{e}^{-\left(\frac{v_{p}}{v_{s}}\right)^{2}}\right]
$$

where $F_{c}, F_{s}$ and $v_{s}$ are the Coulomb friction, viscous friction and stribeck velocity, respectively.

\subsection{Internal leakage model}

At small servo valve spool displacements, the leakage flow between the valve spool and body dominates the orifice flow through the valve ${ }^{[15]}$. In precision positioning applications, where the servo valve operates within the null region, this flow, if ignored, may severely degrade the performance of a conventional servo hydraulic design.

In this study, an accurate model of leakage flow ${ }^{[15]}$ that takes into consideration the leakage flow and orifice flow is applied. By making smooth transition between them would likely improve the precision of the servo hydraulic system design and performance. The model used is a nonlinear servo valve model that accurately captures the servo valve leakage behavior over the whole range of spool movement. The leakage behavior is modeled as turbulent flow with a flow area inversely proportional to the overlap between the spool areas and the servo valve orifices.

A servo valve configuration depicted in Fig. 3 consists of two control ports with variable orifices which regulate the flow rates. The flow rates through the control ports of the servo valve are expressed in (19), and the flow rate at the supply and return ports are represented in (20).

$$
\begin{aligned}
& Q_{1}=Q_{I S}-Q_{I R} \text { and } Q_{2}=Q_{2 R}-Q_{2 S} \\
& Q_{S}=Q_{I S}+Q_{2 S} \text { and } Q_{R}=Q_{I R}-Q_{2 R}
\end{aligned}
$$

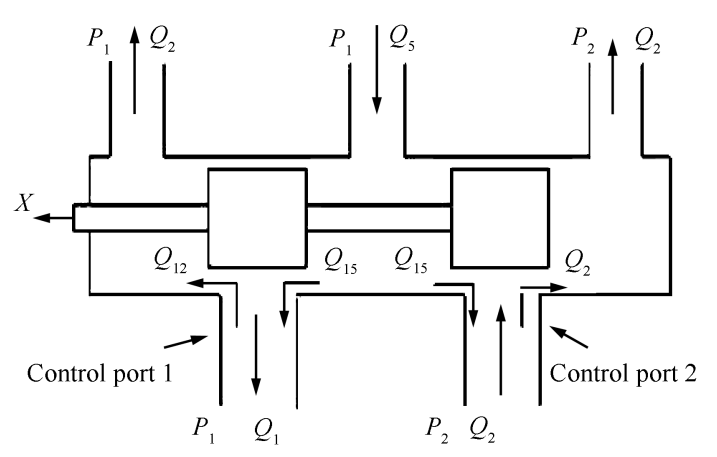

Fig. 3 Hydraulic servo valve configuration

The flow rates at the supply side and return side of control port 1 are given by

$$
\begin{aligned}
& \left.Q_{I S}=K_{I S} \sqrt{P_{S}-P_{I}} X_{0}+X_{v}\right), \quad X_{v} \leqslant 0 \\
& Q_{I R}=K_{I R} \sqrt{P_{I}-P_{R}} X_{0}^{2}\left(X_{0}+k_{I R} X_{v}\right)^{-1}, \quad X_{v} \geqslant 0
\end{aligned}
$$

where $X_{0}$ is the leakage flow rate at null $\left(X_{v}=0\right) . X_{0}$ is equivalent to a spool displacement that would result in the same amount of flow in a nonleaking servo valve as the leakage flow rate in a leaking servo valve with a centered spool. Since the leakage resistance increases at larger valve openings, the leakage flow rate is inversely proportional to the spool displacement ${ }^{[15]}$.

The relations for orifice and leakage flow at the servo valve ports form the basis of the servo valve flow model. For a negative spool displacement, the flow relations are interchanged since now the supply side forms the leakage path and the return side flow is an orifice flow. Applying similar reasoning to each orifice, we obtain the flow relations for control port $1^{[15]}$ as

$$
\begin{gathered}
Q_{I S}=K_{I S}\left(P_{S}-P_{I}\right)^{\frac{1}{2}} \begin{cases}\left(X_{0}+X_{V}\right), & X_{V} \geqslant 0 \\
X_{0}^{2}\left(X_{0}-k_{I S X_{V}}\right)^{-1}, & X_{V}<0\end{cases} \\
Q_{I R}=K_{I R}\left(P_{I}-P_{R}\right)^{\frac{1}{2}} \begin{cases}X_{0}^{2}\left(X_{0}+k_{I R} X_{V}\right)^{-1}, & X_{V} \geqslant 0 \\
X_{0}-X_{V}, & X_{V}<0 .\end{cases}
\end{gathered}
$$

For control port 2, the flow relations are

$$
\begin{aligned}
& Q_{2 S}=K_{2 S}\left(P_{S}-P_{2}\right)^{\frac{1}{2}}\left\{\begin{array}{lr}
X_{0}^{2}\left(X_{0}-k_{2 S X_{V}}\right)^{-1}, & X_{V} \geqslant 0 \\
\left(X_{0}-X_{V}\right), & X_{V}<0 .
\end{array}\right. \\
& Q_{2 R}=K_{2 R}\left(P_{2}-P_{R}\right)^{\frac{1}{2}} \begin{cases}\left(X_{0}+X_{V}\right), & X_{V} \geqslant 0 \\
X_{0}^{2}\left(X_{0}-k_{2 R} X_{V}\right)^{-1}, & X_{V}<0 .\end{cases}
\end{aligned}
$$

The total supply flow $Q_{S}$ represents the internal leakage flow since the control ports are blocked for an internal leakage test ${ }^{[5]}$. The internal leakage flow can be expressed by

$$
Q_{S}=2 K_{f}\left(P_{S}-P_{R}\right)^{2}\left(X_{0}+\left|X_{V}\right|\right)(1+f(X))^{2}
$$

where

$$
f\left(X_{v}\right)=\left[1+\frac{\left|X_{v}\right|}{X_{0}}\right]^{2}\left[1+k_{f} \frac{\left|X_{v}\right|}{X_{0}}\right]^{2}
$$

Having discussed the electro-hydraulic actuator model, the friction model, and the internal leakage model, we then integrate them into an integrated model. The friction model is integrated by supplying the output of (16)-(18) into the model. The internal leakage model in (23)-(27) are integrated into (6)-(7) to determine the total supply flow into side 1 of the cylinder.

The parameters and values of the system are listed in Table 1 . The servo valve and hydraulic cylinder parameters are obtained from the physical system in [9]. The compatibility of these subsystems has been verified in simulations as well as experimental tests in that study.

The Simulink block diagram of the electro-hydraulic servo system with friction and internal leakage modeled from (1)-(28) is shown in Fig. 4. The next section will discuss the FLC used to control the position of electrohydraulic system (EHS) model that contains friction and internal leakage. 


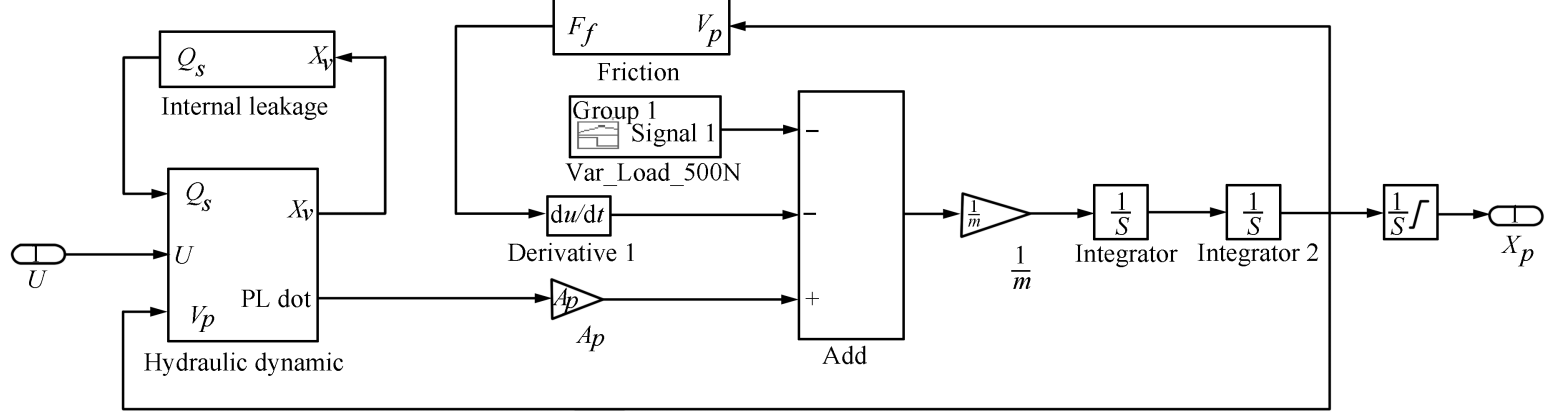

Fig. 4 The simulink block diagram of electro-hydraulic actuator system with friction and internal leakage

Table 1 Parameters of the hydraulic system ${ }^{[4]}$

\begin{tabular}{|c|c|c|}
\hline \multicolumn{3}{|c|}{ Cylinder } \\
\hline$P_{S}$ & Supply pressure $(\mathrm{Pa})$ & $0.7 \times 10^{7}$ \\
\hline$P_{R}$ & Return pressure $(\mathrm{Pa})$ & 0 \\
\hline$V_{t}$ & Total actuator volume $\left(\mathrm{m}^{3}\right)$ & $0.89 \times 10^{-3}$ \\
\hline$A_{p}$ & Actuator ram area $\left(\mathrm{m}^{2}\right)$ & $2.97 \times 10^{-3}$ \\
\hline$L$ & Total stroke of piston $(\mathrm{m})$ & 0.3 \\
\hline$m$ & Total mass of piston and load (kg) & 18 \\
\hline$\beta_{e}$ & Effective bulk modulus $(\mathrm{Pa})$ & $1 \times 10^{9}$ \\
\hline$\rho$ & Fluid mass density $\left(\mathrm{kg} / \mathrm{m}^{2}\right)$ & 850 \\
\hline \multicolumn{3}{|c|}{ Servo valve } \\
\hline$C_{d}$ & Discharge coefficient & 0.6 \\
\hline$C_{t}$ & Total leakage coefficient & $2 \times 10^{-14}$ \\
\hline$W$ & Spool valve area gradient $\left(\mathrm{m}^{2}\right)$ & 0.02 \\
\hline$k_{v}$ & Servo valve spool position gain $(\mathrm{m} / \mathrm{V})$ & $1.27 \times 10^{-5}$ \\
\hline \multicolumn{3}{|c|}{ Leakage parameter } \\
\hline$X_{0}$ & Equivalent orifice opening $(\mathrm{m})$ & $\begin{array}{c}8 \times 10^{-5}, 43 \times 10^{-5} \\
235 \times 10^{-5}\end{array}$ \\
\hline$k_{f}$ & Leakage coefficient & 0.3 \\
\hline$K_{f}$ & Flow gain & $1.42 \times 10^{-5}$ \\
\hline \multicolumn{3}{|c|}{ Friction parameter } \\
\hline$F_{S}$ & Static friction $(\mathrm{N})$ & 300 \\
\hline$F_{C}$ & Coulomb friction $(\mathrm{N})$ & 230 \\
\hline$\sigma_{0}$ & Bristles stiffness coefficient $(\mathrm{N} / \mathrm{m})$ & $14 \times 10^{5}$ \\
\hline$\sigma_{1}$ & Bristles damping coefficient (Ns/m) & 340 \\
\hline$\sigma_{2}$ & Viscous friction $(\mathrm{Ns} / \mathrm{m})$ & 70 \\
\hline$V_{S}$ & Stribeck velocity $(\mathrm{m} / \mathrm{s})$ & 0.05 \\
\hline
\end{tabular}

\section{Fuzzy logic controller}

\subsection{Fuzzy inference system}

The control strategy of the EHAS needs to be able to overcome the nonlinearities and uncertainties emerging from the system. A controller with robust tracking performance is obviously significant. A fuzzy logic controller is designed to fulfil the need for such a controller.

Fuzzy control can provide a formal methodology for representing, manipulating, and implementing a humans heuristic knowledge about how to control a system ${ }^{[9]}$. The fuzzy logic controller block diagram is given in Fig. 5 .

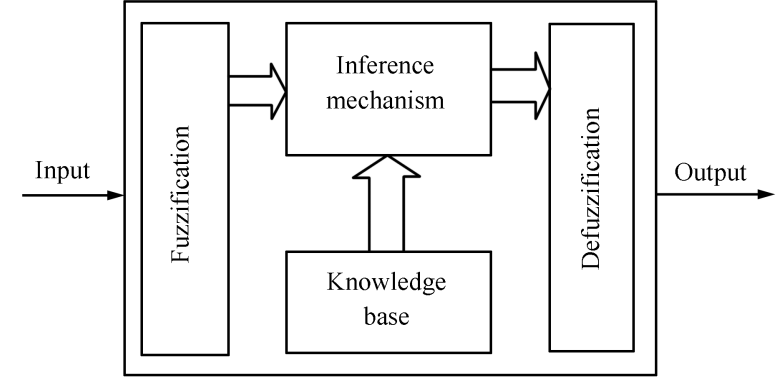

Fig. 5 The fuzzy logic controller block diagram

The fuzzy controller has four main components: 1) The "rule-base" holds the knowledge in the form of a set of rules of how to control the system best. 2) The inference mechanism evaluates which control rules are relevant at the current time and then decides what the input to the plant should be. 3) The fuzzification interface simply modifies the inputs so that they can be interpreted and compared to the rules in the rule-base. 4) The defuzzification interface converts the conclusions reached by the inference mechanism into the inputs to the plant ${ }^{[16]}$.

\subsection{Universe of discourse and membership functions}

The universe of discourse in the fuzzy membership function designed for the error, change of error and the output is normalized with $[-1,1]$. The linguistic values of the error and change of error are designed with 7 linguistic terms for each input: negative big (NB), negative medium (NM), negative small (NS), zero (Z), positive small (PS), positive medium (PM), and positive big (PB). The same linguistic terms are used for the output. Each linguistic value is assigned a triangular membership function. The membership functions of inputs and output are shown in Figs. 6-8.

\subsection{Rules}

Using the 7 linguistic values for each input and 7 values for the output, the FLC is designed with 49 rules in this study. These rules were selected using the trial and error method. The rule base is presented in Table 2 . 


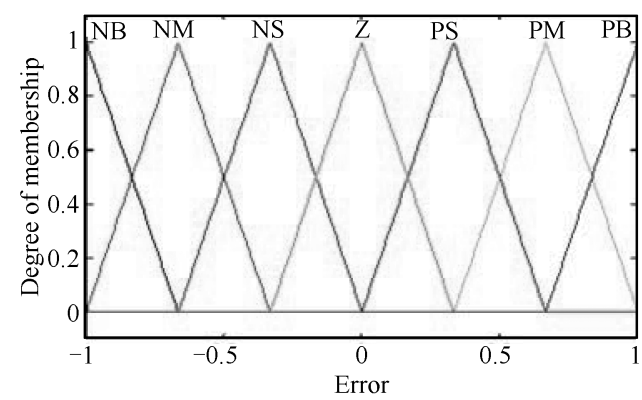

Fig. 6 Membership functions of error as input

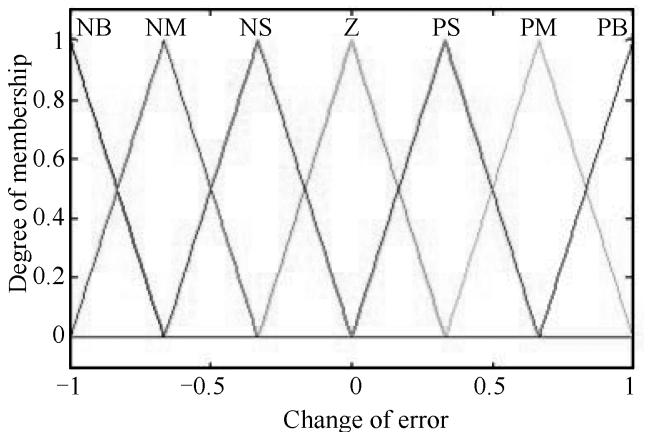

Fig. 7 Membership functions of change of error as input

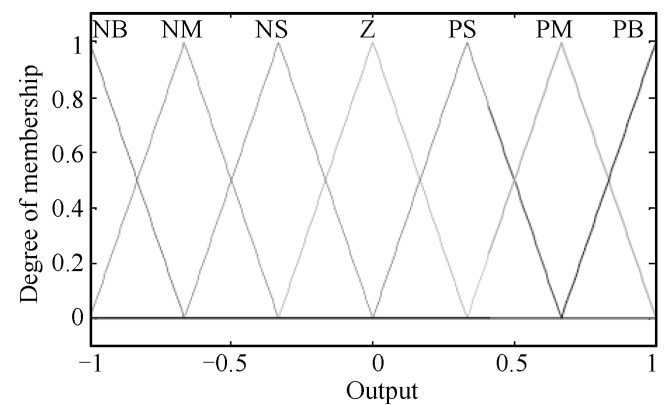

Fig. 8 Membership functions of control signal as output

Table 2 Rule base of the FLC

\begin{tabular}{cccccccc}
\hline $\mathrm{E}$ & $\mathrm{PB}$ & $\mathrm{PM}$ & $\mathrm{PS}$ & $\mathrm{Z}$ & $\mathrm{NS}$ & $\mathrm{NM}$ & $\mathrm{NB}$ \\
$\Delta \mathrm{E}$ & & & & & & & \\
\hline PB & PB & PB & PM & PM & PS & PS & Z \\
PM & PB & PM & PM & PS & PS & Z & NS \\
PS & PM & PM & PS & PS & PZ & NS & NS \\
Z & PM & PS & PS & Z & NS & NS & NM \\
NS & PS & PS & Z & NS & NS & NM & NB \\
NM & PS & Z & NS & NS & NM & NB & NB \\
NB & Z & NS & NS & NM & NB & NB & NB \\
\hline
\end{tabular}

\subsection{PI-like FLC}

The FLC is designed as a PI fuzzy logic controller where the equality of the PI-controller is

$$
\mathrm{d} u=K_{i} \times e(t)+K_{p} \times \frac{\mathrm{d} e}{\mathrm{~d} t}
$$

with

$$
u=u_{0}+K_{u} \times \mathrm{d} u
$$

where $K_{p}$ and $K_{i}$ are the proportional and the integral gain coefficients, respectively, $u_{0}$ is the output of the controller in the previous sampling time and $K_{u}$ is the output scaling factor. A block diagram for a PI like fuzzy logic control system is depicted in Fig. $9^{[17]}$

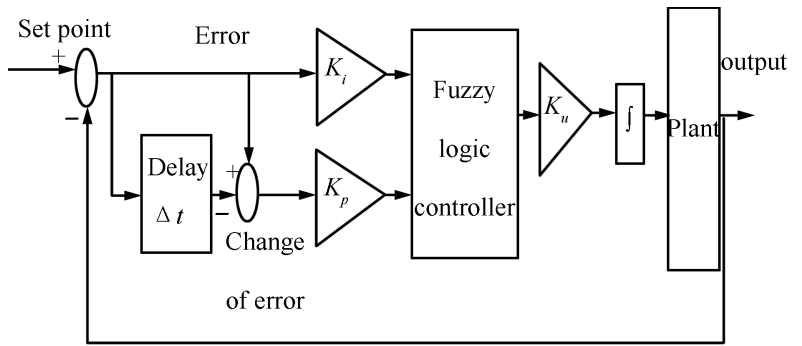

Fig. 9 Block diagram of a PI-like fuzzy logic control system

Based on Fig. 9, it is clear that the FLC has two input variables: error and change of error. The output variable of the controller is the control signal to control the plant. Thus, the FLC is a two-inputs and one-output system.

After the design of FLC, it is connected with the plant which is the integrated model of the electro-hydraulic system to be controlled. This forms a closed loop system with the FLC as the controller, and the output of the plant is observed as the feedback to control system. The system output is denoted by $y(t)$, its inputs are denoted by $u(t)$, and the reference input to the fuzzy logic controller is denoted by $r(t)$ as shown in Fig. 10. The Simulink block diagram of the closed loop system is depicted in Fig. 11.

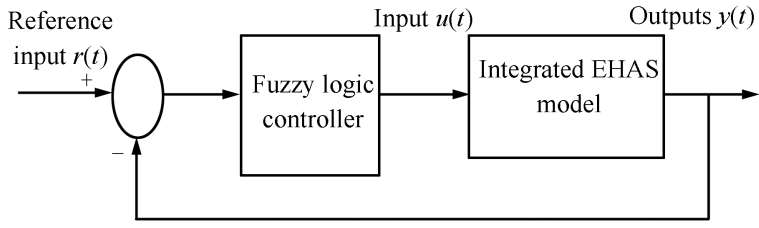

Fig. 10 Fuzzy logic controlled integrated hydraulic model in a closed-loop control system

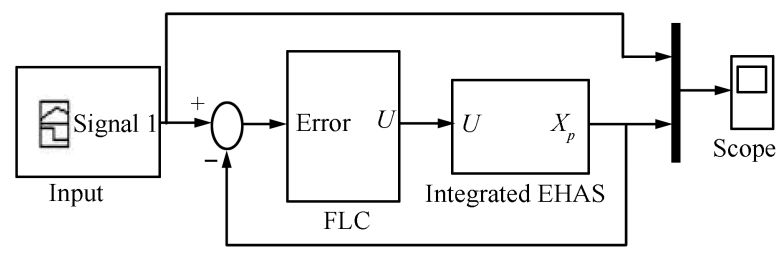

Fig. 11 Simulink block of the FLC controlled integrated EHAS in closed loop system

\subsection{FLC tuning}

The rest of the process will be the simulation of the whole system and the tuning of the FLC. The objective is to obtain the best system performance. This can be accomplished by tuning the values of scaling factors: $K_{p}, K_{i}$ and $K_{u}$ that can result in the minimum oscillation, overshoot and error in position.

Tuning of FLC parameters using the trial and error method does not always give the optimum results. In ad- 
dition, it is a time consuming process. Therefore, an intelligent optimization technique to optimize the FLC parameters is obviously necessary. The next section discusses the particle swarm optimization.

\section{Particle swarm optimization}

In 1995, Kennedy and Eberhart introduced particle swarm optimization as an evolutionary algorithm. PSO was inspired by swarming behaviors observed in flocks of birds, schools of fish, or swarms of bees. PSO is a populationbased optimization tool, which could be implemented and applied to solve various function optimization problems, or the problems that can be transformed to function optimization problems. This method was developed through simulation of a simplified social system, and has been found to be robust in solving continuous nonlinear optimization problems $^{[18]}$.

In PSO, each particle is attracted toward the position of current global best $g^{*}$ and its own best location $x_{i}^{*}$ in history, and at the same time, it has tendency to move randomly. When a particle finds a location that is better than previously found locations, then it updates the location as the new current best location for particle $i$. There is a current best location for all $n$ particles at any time $t$ during iterations. The aim is to find the global best solution among all the current best solutions until the objective no longer improves or after a certain number of iterations. The essential steps of the PSO can be summarized as the pseudo code ${ }^{[13]}$ :

Particle swarm optimization

Objective function $f(x), x=\left(x_{1}, \cdots, x_{p}\right)^{1}$

Initialize locations $x_{i}$ and velocities $v_{i}$ of $n$ particles

Find $g^{*}$ from $\min \left\{f\left(x_{1}\right), \cdots, f\left(x_{n}\right)\right\}($ at $t=0)$

While (criterion)

$T=t+1$ (pseudo time or iteration counter)

For loop over all $n$ particles and all $d$ dimensions

Generate new velocity $v_{i}^{t+1}$ using (30)

Evaluate objective functions at new locations $x_{i}^{t+1}$

Find the current best location for each particle $x_{i}^{*}$

End for

Find the current global best $g^{*}$

End while

Output the final results $x_{i}^{*}$ and $g^{*}$

When $x_{i}$ and $v_{i}$ are the position vector and velocity for particle $i$, the new vector is determined by

$$
v_{i}^{t+1}=v_{i}^{t}+\alpha_{1} \times\left[g^{*}-x_{i}^{t+1}\right]+\beta_{2} \times\left[x_{i}-x_{i}^{t}\right]
$$

where $\alpha_{1}$ and $\beta_{2}$ are two random vectors, and each entry takes the value between 0 and 1. Parameters $\alpha$ and $\beta$ are the learning parameters or acceleration constants, which can be typically taken as $2^{[19]}$.

\subsection{Accelerated PSO}

The accelerated PSO based on [19] is employed in this study. The standard PSO uses both the current global best $g^{*}$ and the individual best $x_{i}^{*}$. The reason of using the individual best particle is primarily to increase the diversity in the quality solutions. However, this diversity can be simulated using some randomness. Subsequently, there is no compelling reason for using the individual best particle, unless the optimization problem of interest is highly nonlinear and multimodal ${ }^{[19]}$.
As discussed in [19], a simplified version which could accelerate the convergence of the algorithm is to use the global best particle only. Thus, in the accelerated PSO, the velocity vector is generated by $E$

$$
v_{i}^{t+1}=v_{i}^{t}+\alpha\left(E-\frac{1}{2}\right)+\beta\left(g^{*}-x_{i}^{t}\right)
$$

where $E$ is a random variable with values ranging from 0 to 1 . We can also use a standard normal distribution $\alpha E_{n}$, where $E_{n}$ is drawn from $N(0,1)$ to replace the second term. The update of the position is

$$
x_{i}^{t+1}=x_{i}^{t}+v_{i}^{t+1} .
$$

In order to increase the convergence even further, the update of the location in a single step can also be written as

$$
x_{i}^{t+1}=(1-\beta) x_{i}^{t}+\beta g^{*}+\alpha E_{n} .
$$

This simpler version will give the same order of convergence. The typical values for this accelerated PSO are $\alpha \approx 0.1 \sim 0.7$, though $\alpha \approx 0.2$ and $\beta \approx 0.5$ can be taken as the initial values for most unimodal objective functions. It is worth pointing out that parameters $\alpha$ and $\beta$ should be related to the scales of the independent variables $x_{i}$ and the search domain in general.

A further improvement to the accelerated PSO used in [19] is to reduce the randomness as iterations proceed. This means that we can use a monotonically decreasing function such as

$$
\alpha=\alpha_{0} \mathrm{e}^{-\gamma t}
$$

or

$$
\alpha=\alpha_{0} \gamma^{t}, \quad 0<\gamma<1
$$

where $\alpha \approx 0.5 \sim 1$ is the initial value of the randomness parameter. Here, $t$ is the number of iterations or time steps, $0<\gamma<1$ is a control parameter, where $t \in[0,10]$. Obviously, these parameters are fine-tuned to suit the current optimization problem.

\subsection{PSO implementation}

The parameters used in the PSO are as follows:

Number of particles: 25,

Dimension of the problem: 3 ,

Number of maximum iterations: 500 ,

Speed of convergence ( $\beta=$ acceleration coefficient determining the scale of the forces in the direction of $\left.p_{i}\right): 0.5$,

Randomness amplitude of roaming particles $(\alpha=$ acceleration coefficient determining the scale of the forces in the direction of $\left.g_{i}\right): 0.2$,

$$
\gamma=0.95 \text {. }
$$

The PSO is employed to optimize the FLC parameters (scaling factors): $K_{i}, K_{p}, K_{u}$. These factors are optimized at the same time. The function of these parameters in the FLC is shown as

$$
\Delta u(t)=K_{i} \times e(t)+K_{p} \times \Delta e(t) .
$$


The fitness function of the problem is the integral of time multiplied by absolute errors (ITAE) as

$$
I_{\mathrm{ITAE}}=\int_{0}^{T} t|e(t)| \mathrm{d} t
$$

The fitness function considered is based on the error criterion. The performance of a controller is evaluated in terms of error criterion. Fig. 12 shows the closed loop system of the integrated EHAS controlled by PSO optimized FLC.

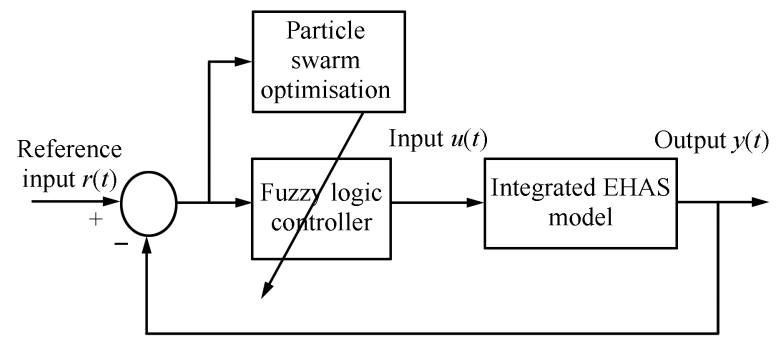

Fig. 12 Closed loop control system of integrated EHAS controlled by PSO optimized FLC

\section{$5 \quad$ Tests and simulations}

The simulation tests are conducted to evaluate the performance of the closed loop system under the prescribed environments. The tests are conducted using variable load with $500 \mathrm{~N}$ maximum value of the load, friction parameters specified in Table 1, and the values of orifice opening which represent internal leakage. The variable load is depicted in Fig. 13.

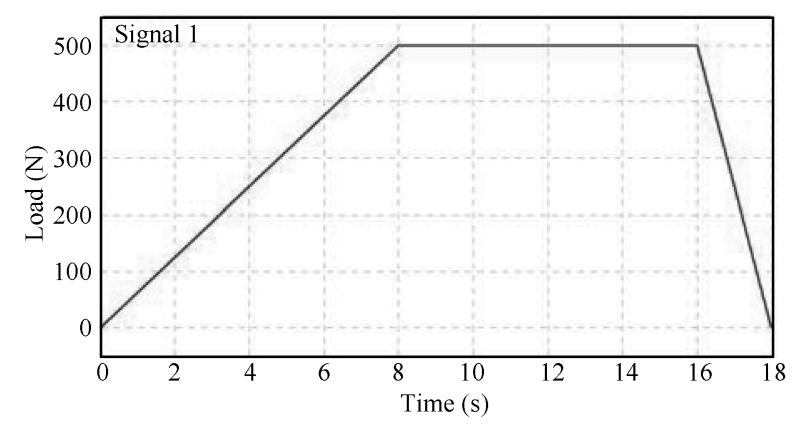

Fig. 13 Variable load of the closed loop system

Tests and simulations are conducted to assess the system performance with respect to the type of reference signals and orifice openings. These consist of two steps:

1) The first test is undertaken to investigate the system performance to respond to different reference signals in the presence of friction and internal leakage. It is conducted by applying two different reference signals and comparing performance of the FLC with the conventional PID controller. The FLC performance is investigated in both unoptimized and optimized conditions. The first reference is a signal which simulates the EHAS trajectory in excavator, while the second one is the sinusoidal signal. The variable load is used for simulated reference signal for both controllers, while the friction and internal leakage are used in the tests for both reference signals and controllers. The orifice open- ing to represent the internal leakage is $8 \times 10^{-5} \mathrm{~m}$ to coincide with [9]. The friction parameters and values applied to the tests are listed in Table 1.

2) The second test is conducted to investigate the system response to different orifice openings which represent internal leakage. A low level opening of $8 \times 10^{-5} \mathrm{~m}$ is used in Test 1 . The opening is then increased until chattering occurs, while the proposed controller is in place. This opening is then used as the high level of the opening. Then, the system response to low level opening in Test 1 is compared to the response to high level one in this test. Both reference signals are used in these tests to compare the FLC performance to the PID controllers, where the FLC is tested both in unoptimized and optimized settings.

In both tests, ITAE is used as the index of the tracking performance.

\section{System stability}

The stability analysis methods enable the design of fuzzy logic control system, while providing conditions that permit parameter setting for FLCs. In principle, for the stability analysis of fuzzy logic control systems controlling nonlinear processes, we use method suitable for the analysis of the nonlinear dynamical system ${ }^{[20]}$. Which method is the best one to use depends only on the prerequisites, which are the structure of the system, the type of information describing the process, and the type of sufficient conditions for the stability. There are a number of studies in stability analysis of fuzzy logic control systems with Mamdani type FLCs. They include the Lyapunov's ${ }^{[21]}$ and Krasovskii' ${ }^{[22]}$ approaches, the describing function method ${ }^{[20]}$, the algebraic approaches ${ }^{[23]}$, or the use of Mamdani fuzzy dynamic models $^{[24]}$.

The new stability analysis approach proposed in [25] is employed as the foundation in this study. In several essential aspects, it is different from the application of Lyapunov's theorem $^{[20,26]}$, and it allows more applications. Specifically, it is suitable to control the processes where the derivative of the Lyapunov function candidate is not negative definite. Therefore, applying LaSalle's invariance principle to the nonlinear processes controlled by Mamdani type FLCs can be applicable to a wide area of nonlinear dynamic systems. Another important difference is that the stability of the closed-loop system is guaranteed by the stability of each fuzzy subsystem.

Consider a single input $n$ order nonlinear system

$$
\dot{x}=f(x)+b(x) u
$$

where $x$ is the state vector, $f(x)$ and $b(x)$ are the dynamics describing dynamics of the plant, and $u$ is the control input of the plant, whose value is determined by an FLC with inputs depending on $x$. It has been proved in [27] that if every rule of the FLC applying to the plant individually gives a stable subsystem in the sense of Lyapunov (ISL) in the active region of the fuzzy rule subject to a common Lyapunov function, the whole fuzzy logic control system is stable in the sense of Lyapunov.

It was discussed in [25] that a fuzzy logic control system consists of a process and a fuzzy logic controller (FLC). Let $X \in \mathbf{R}^{n}$ be a universe of discourse. The following class of 
single input nonlinear dynamical systems modeled by the state-space equations is accepted.

$$
\dot{x}=f(x)+b(x) u
$$

where $x \in X, x=\left[\begin{array}{ll}x_{1} & x_{2} \cdots x_{n}\end{array}\right]^{\mathrm{T}}$ is the state vector, and

$$
\dot{x}=\left[\begin{array}{ll}
\dot{x}_{1} & \dot{x}_{2} \cdots \dot{x}_{n}
\end{array}\right]^{\mathrm{T}}
$$

is the derivative of $x$ with respect to the time variable $t$,

$$
b(x)=\left[b_{1}(x) b_{2}(x) \cdots b_{n}(x)\right]^{\mathrm{T}}
$$

are functions describing the dynamics of the process, and $u$ is the control signal fed to the process, obtained by the centre of gravity (COG) defuzzification method for Mamdani type fuzzy logic.

In [25], it was proved that if each subsystem is stable in the sense of Lyapunov. Under a common Lyapunov function, the overall system will be also stable in the sense of Lyapunov. In these conditions, it is guaranteed that the equilibrium point at the origin is globally asymptotically stable. Theorem 1 in [25] states that if $P$ is a positive definite matrix and

1) $V(x)=x^{\mathrm{T}} P x \rightarrow \sim$ as $\|x\| \rightarrow \sim, V(0)=0$.

2) $V(x) \leqslant 0, \forall x \in X$ for all fuzzy subsystems.

3) The set $\{x \in X \mid \dot{V}(X)=0\}$ contains no trajectory of the system except the trivial trajectory $x(t)=0$ for $t \geqslant 0$, then, a fuzzy logic controller with the AND-SUM-COG is globally asymptotically stable at the origin.

The fuzzy logic controller defined in Section 3 with ANDSUM-COG can fulfill the one defined in [25, 27]. According to Theorem 1 in [25] and Lemma 3.1 in [27], the closed loop system in Fig. 10 is then simulated to analyse the response. The simulation result is depicted in Fig. 14. The result shows that input, output and the control signal converge for $t \geqslant 0$. This indicates that the fuzzy logic control system is globally asymptotically stable.

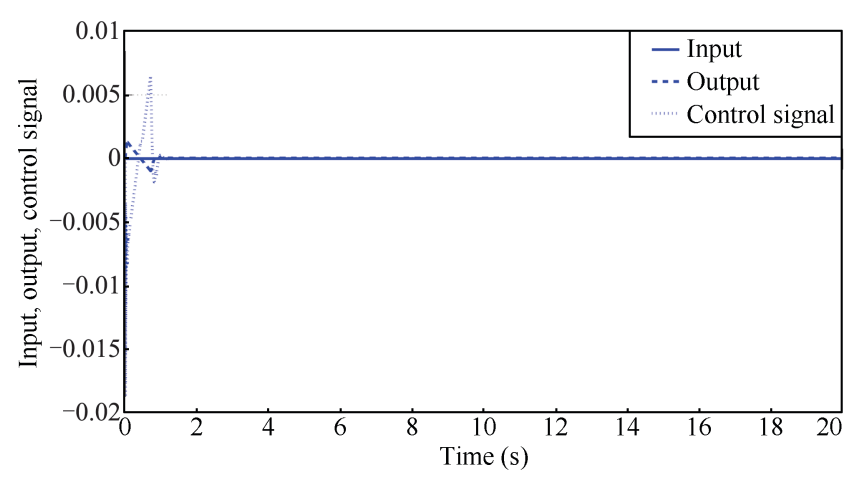

Fig. 14 Response of the system stability test

\section{Results and discussion}

By applying simulated reference input with $8 \times 10^{-5} \mathrm{~m}$ orifice opening, Figs. 15 and 16 show the responses of the systems using the unoptimized FLC and PID controllers, respectively. It can be observed that the FLC is able to track the reference accurately without overshoot, chattering and steady state error, so that it does not need to be optimized. The ITAE of this test is 0.0089 . The PID controller tracks the reference with a delay time up to $2 \mathrm{~s}$, overshoot of $5 \%$ and ITAE of 0.4904. It can also be assessed, that the ITAE for PID is higher than the one for FLC with significant difference. This indicates that the performance of FLC is better than that of the PID in this test.

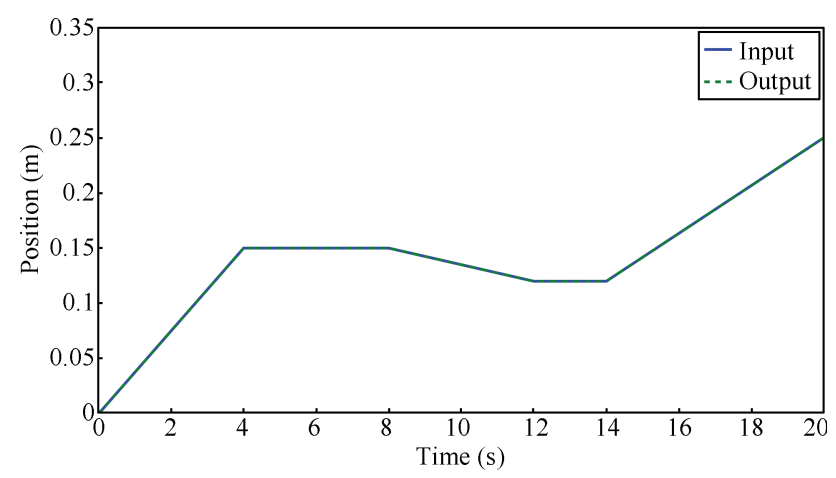

Fig. 15 Response of the system using unoptimized FLC with simulated reference signal and $8 \times 10^{-5} \mathrm{~m}$ orifice opening

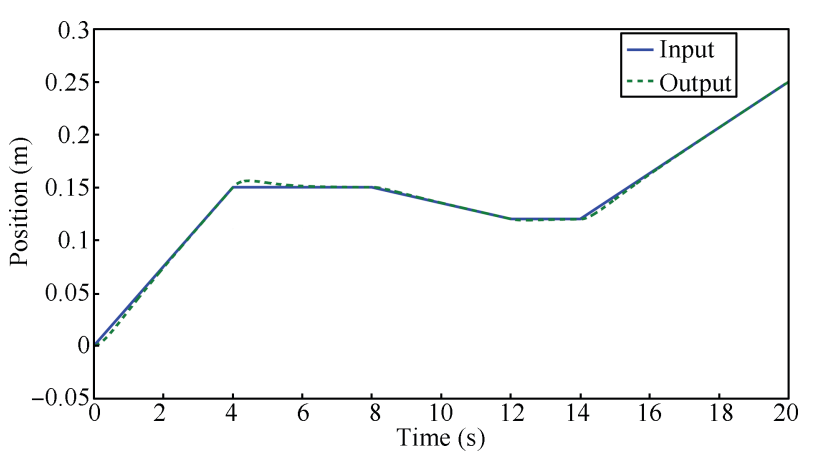

Fig. 16 Response of the system using PID controller with simulated reference signal and $8 \times 10^{-5} \mathrm{~m}$ orifice opening

Using the same orifice opening and friction parameters, both of the controllers are tested with sinusoidal signal reference. Position response of the system for unoptimized FLC and PID controllers are shown in Figs.17 and 18, respectively. It can be seen from Fig. 17 that the unoptimized FLC performs satisfactorily to track the reference without errors, delay and chattering. The ITAE of this test is 0.0164 . Fig. 18 shows that although the PID controller is able to track the position reference, it still introduces delay between $0 \mathrm{~s}$ and $2 \mathrm{~s}$, where the ITAE of this test is 0.8114 .

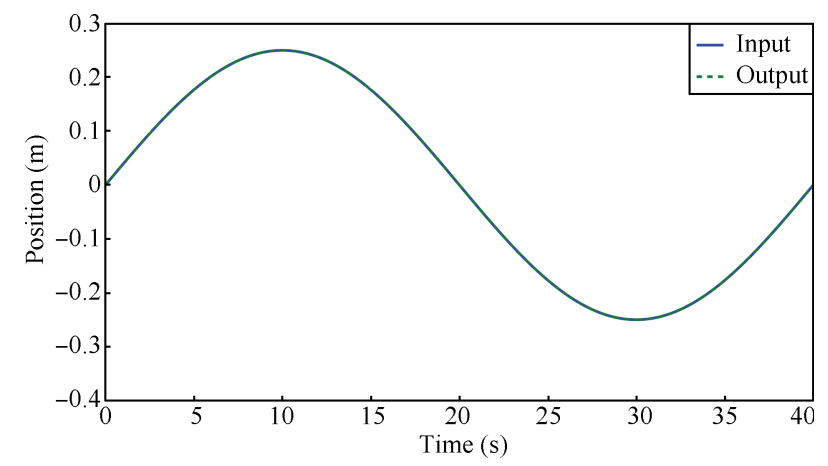

Fig. 17 Response of the system using unoptimized FLC with sinusoidal reference and $8 \times 10^{-5} \mathrm{~m}$ orifice opening

The second test is conducted for both FLC and PID con- 
trollers by increasing orifice opening until the first observable chattering occurs. For simulated reference, the first observable chattering is noticed at $235 \times 10^{-5} \mathrm{~m}$ orifice opening. Figs. 19 and 20 show the responses of the systems using unoptimized FLC and optimized FLC.

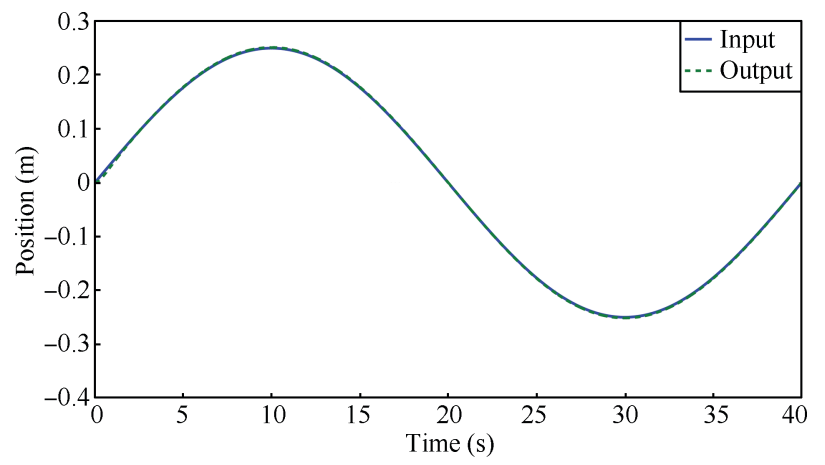

Fig. 18 Response of the system using PID controller with sinusoidal reference and $8 \times 10^{-5} \mathrm{~m}$ orifice opening

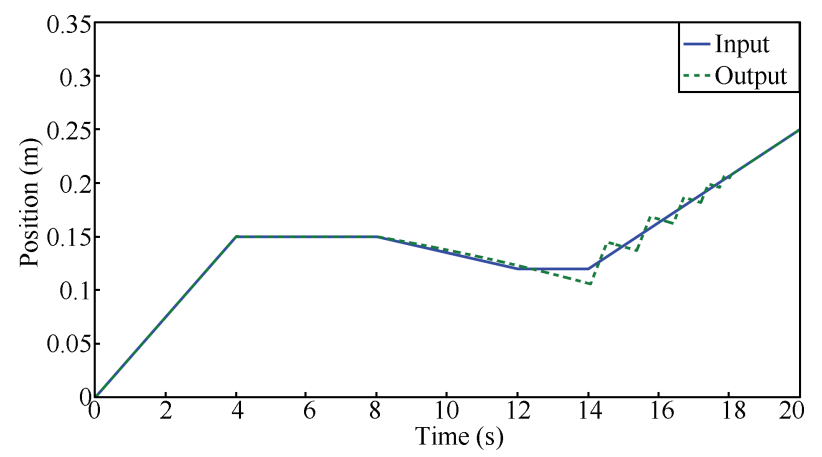

Fig. 19 Response of system using unoptimized FLC with simulated reference signal and $235 \times 10^{-5} \mathrm{~m}$ orifice opening

It can be seen from Fig. 19 that the $235 \times 10^{-5}$ orifice opening introduces deflection and chattering in the system response. The deflection starts from $8 \mathrm{~s}$ when the variable load reaches its maximum value until the chattering occurs from $12.5 \mathrm{~s}$ to $18 \mathrm{~s}$ of the simulation time. After that, the system output is able to track the trajectory reference without error. This indicates that the FLC is not able to handle the nonlinearities in the system introduced by the orifice opening in particular section of the trajectory anymore. The ITAE obtained from this test is 0.8251 .

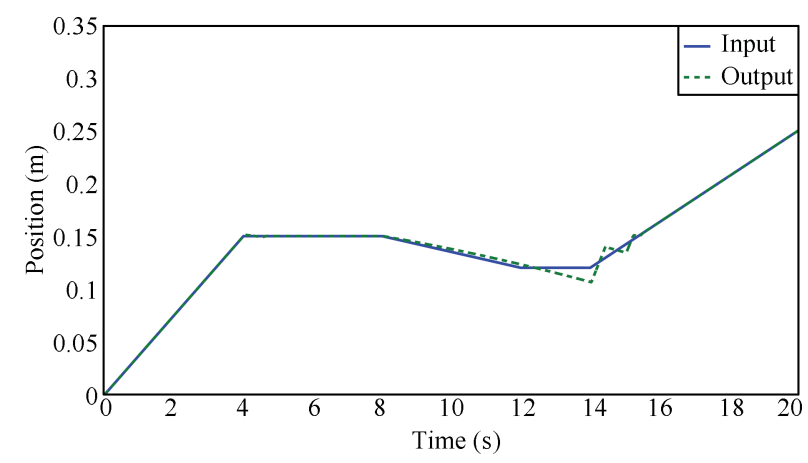

Fig. 20 Response of the system using optimized FLC with simulated reference and $235 \times 10^{-5}$ orifice opening
The next test is undertaken by employing PSO to optimize the FLC parameters, by using the same trajectory reference, variable load, friction parameters, and orifice opening. The converged result of the optimized parameters are obtained: $K_{p}=200.4922, K_{i}=4.278447$, and $K_{u}$ $=17.44137$. The result in Fig. 20 shows that the PSO optimized FLC reduces the chattering so that it occurs from $14 \mathrm{~s}$ to $15.2 \mathrm{~s}$. It is also observed that there is no delay, or overshoot or tracking errors in the system response, where the ITAE of this test is 0.5704 .

For PID controller, it is observed in Fig. 21 that it contributes oscillation from $4 \mathrm{~s}$ to $11.5 \mathrm{~s}$ and $12 \mathrm{~s}$ to $18 \mathrm{~s}$. The ITAE of this test is 0.8716 .

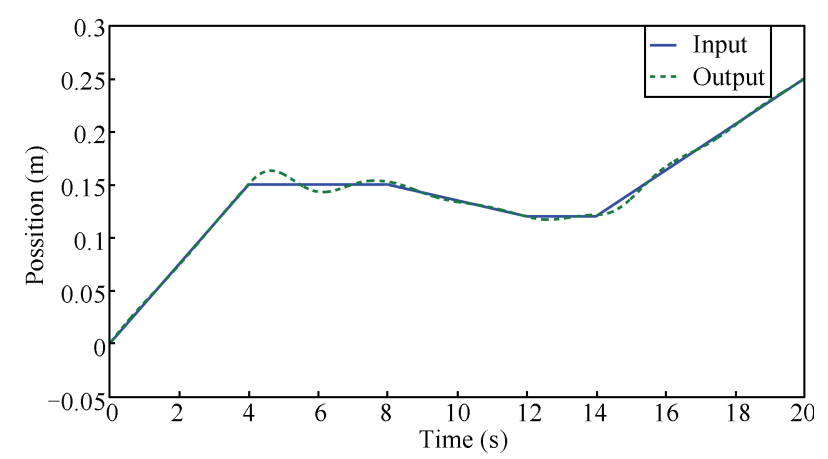

Fig. 21 Response of the system using PID controller with simulated reference and $235 \times 10^{-5}$ orifice opening

For sinusoidal reference, the first observable chattering occurs at $43 \times 10^{-5}$ orifice opening. Position response of the system is depicted in Fig. 22 for unoptimized FLC.

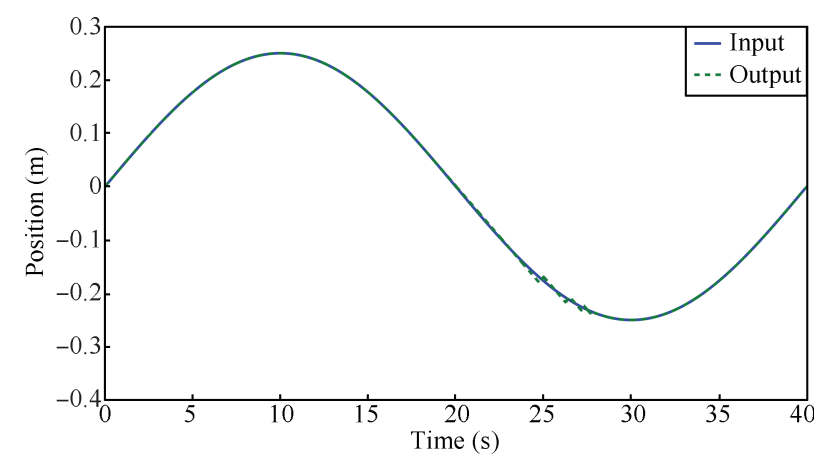

Fig. 22 Response of system using unoptimized FLC with sinusoidal reference signal and $43 \times 10^{-5} \mathrm{~m}$ orifice opening

It is observed from Fig. 22 that the unoptimized FLC is able to track the reference input, while chattering occurs from $23.5 \mathrm{~s}$ to $28 \mathrm{~s}$ with ITAE $=0.5016$. Then, using the optimized FLC parameters, the system response is presented in Fig. 23. The result shows that the optimized FLC by PSO reduces the chattering so that it now occurs from $23.5 \mathrm{~s}$ to $25 \mathrm{~s}$. It can also be seen that there is no delay or tracking error in the system response where the ITAE is 0.3374 .

For PID controller, the result is depicted in Fig. 24. It shows that there is a delay of $2.5 \mathrm{~s}$, and errors in tracking occur between $6 \mathrm{~s}$ to $17.5 \mathrm{~s}$ and $24 \mathrm{~s}$ to $36 \mathrm{~s}$. The ITAE ob- 
tained is 2.2378. Figs. 25 and 26 show the close views to highlight the tracking errors.

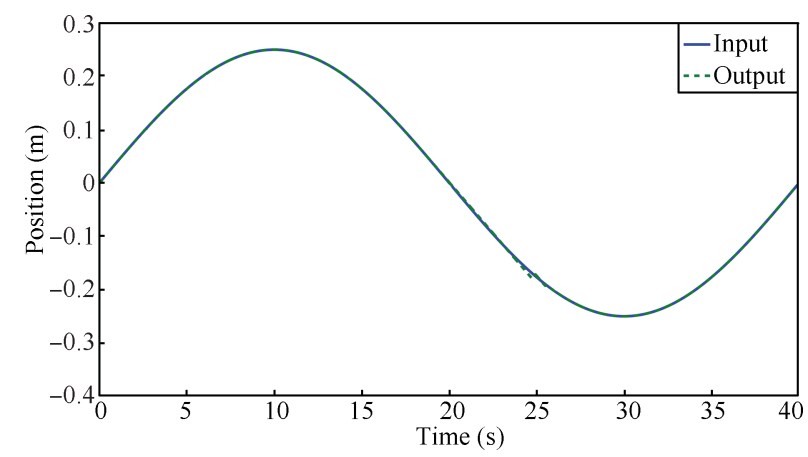

Fig. 23 Response of system using optimized FLC with sinusoidal reference signal and $43 \times 10^{-5} \mathrm{~m}$ orifice opening

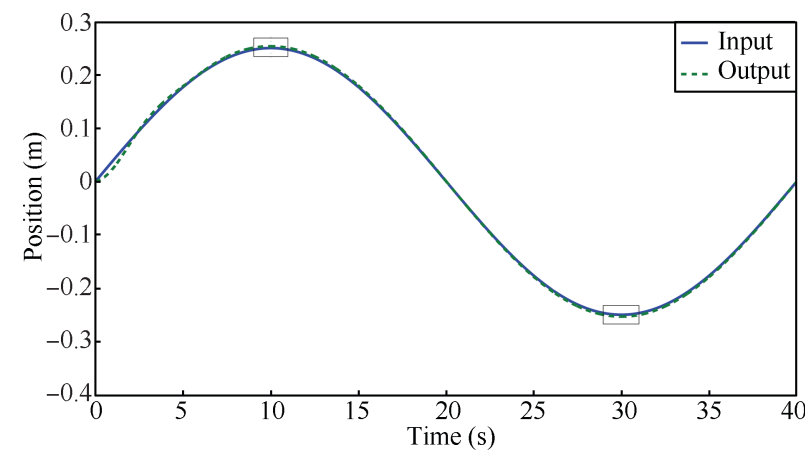

Fig. 24 Response of the system using PID controller with sinusoidal reference and $43 \times 10^{-5} \mathrm{~m}$ orifice opening

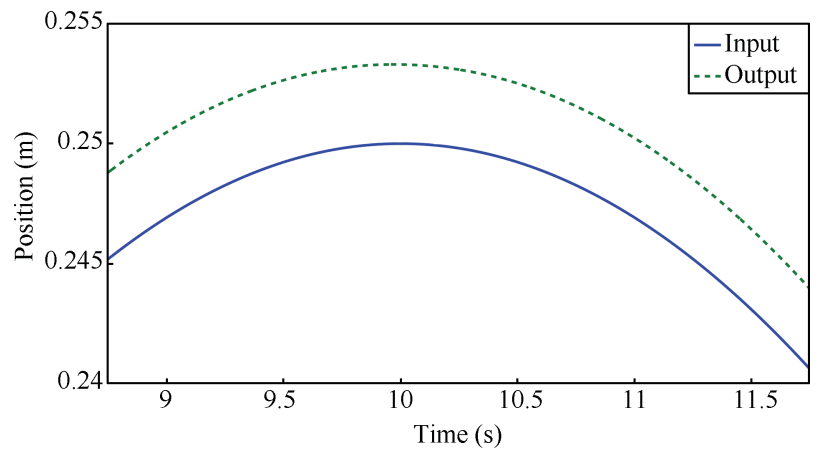

Fig. 25 Close up view of Fig. 23 showing tracking error

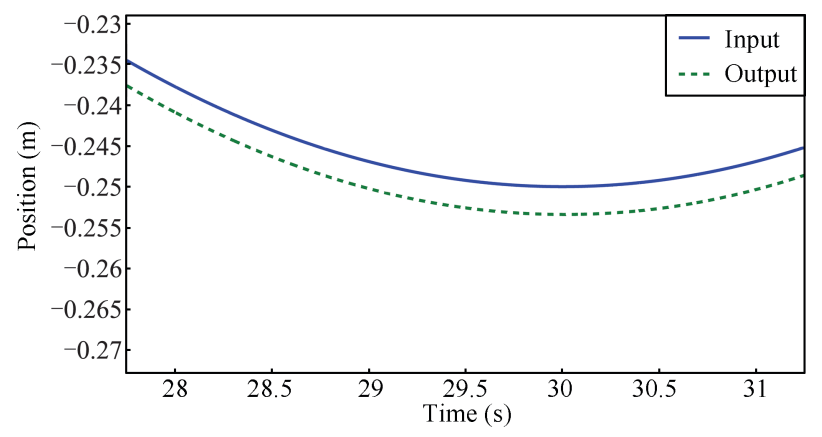

Fig. 26 Tracking errors seen between $27.75 \mathrm{~s}$ and $31.25 \mathrm{~s}$ of Fig. 23
Based on the preceding results, it is obvious that in the first test, the unoptimized FLC is able to track both types of reference trajectories in the presence of friction and internal leakage with good performance. Although the PID controller can track both of the reference trajectories, it introduces delay time and overshoot. For both reference trajectories, the ITAEs of the unoptimized FLC are lower than the ITAE of PID controller, which means that the FLC performs better than the PID controller for both trajectories.

In the second test, the unoptimized FLC is not able to handle the orifice opening of $235 \times 10^{-5} \mathrm{~m}$, where the first observable chattering occurs. When the PSO is employed to optimize the FLC, it is able to reduce the chattering significantly in the presence of friction and internal leakage. The system response using PID controller shows that the increased orifice opening contributes the delay and tracking errors. The ITAE of the optimized FLC is lower than that of the unoptimized FLC, which indicates the effectiveness of the PSO to optimize the parameters of FLC. The ITAE of PID controller is higher than that of both the unoptimized and optimized FLCs. This indicates that both the unoptimized and optimized FLCs outperform the PID controller.

These results show that the increased orifice opening introduces chattering in the system, where the FLC can handle until particular value of opening. Beyond that value, the FLC needs to be optimized by the PSO. This also indicates that for a particular range of internal leakage value, the FLC alone is not sufficient to control the system where the nonlinearities and uncertainties emerge.

These results also show the effectiveness of the PSO to optimize the FLC parameters in order to reduce the chattering introduced by the nonlinearities in the EHAS. These demonstrate that PSO has been successfully implemented to optimize the FLC parameters in the EHAS. It has shown a good performance to handle the friction and internal leakage in the system.

Compared with the PID controller, the proposed controller shows better performance in handling the nonlinearities and uncertainties of the system.

All the results also show that the position responses converge to a steady state value. This results and the discussion in Section 6 indicate that the closed loop control system is stable.

This justifies the ability of the proposed method to improve the tracking performance and robustness to the nonlinearities and uncertainties in the electro-hydraulic actuator system.

\section{Conclusions}

The position control of electro-hydraulic actuator using the proposed method has been presented in this paper. With the friction and internal leakage integrated in the system, the FLC is able to overcome the nonlinearities and uncertainties in the system. For low level values of orifice opening, FLC performs satisfactorily without being optimized by PSO. It outperforms the PID controller to track the reference without delay and overshoot for both types of reference trajectories. 
When larger values of orifice opening are applied, starting from a particular value, the system responses using FLC introduce chattering for both types of reference trajectories. The proposed method shows that it can be reduced significantly by using FLC whose parameters are optimized by PSO. This method also shows that it does not introduce any delay and tracking error compared to the system responses using PID controller which suffers from the errors and delay when larger orifice openings are applied for both types of reference trajectories.

This work justifies that the PSO optimized FLC has been successfully implemented on the position control of EHAS. The proposed controller offers the guaranteed robustness and tracking accuracy of position control in the EHAS applications.

\section{References}

[1] N. H. Quang. Robust Low Level Control of Robotic Excavation, $\mathrm{Ph}$. D. dissertation, University of Sydney, Australia, 2000 .

[2] Q. P. Ha, Q. H. Nguyen, D. C. Rye, H. F. DurrantWhyte. Fuzzy sliding-mode controllers with applications. IEEE Transactions on Industrial Electronics, vol. 48, no. 1, pp. 38-46, 2001.

[3] Q. P. Ha, Q. H. Nguyen, D. C. Rye, H. F. Durrant-Whyte. Impedance control of a hydraulically actuated robotic excavator. Automation in Construction, vol. 9, no. 5-6, pp. 421$435,2000$.

[4] Zulfatman, M. F. Rahmat. Application of self-tuning fuzzy PID controller on industrial hydraulic actuator using system identification approach. International Journal on Smart Sensing and Intelligent Systems, vol. 2, no. 2, pp. 246-261, 2009.

[5] M. Kalyoncu, M. Haydim. Mathematical modelling and fuzzy logic based position control of an electrohydraulic servosystem with internal leakage. Mechatronics, vol. 19, no. 6, pp. 847-858, 2009.

[6] M. M. Lee, H. M. Kim, S. H. Park, J. S. Kim. A position control of electro-hydraulic actuator systems using the adaptive control scheme. In Proceedings of the 7th Asian Control Conference, IEEE, Hong Kong, China, pp. 21-26, 2009.

[7] B. Li, J. Yan, G. Guo, Y. H. Zeng, W. X. Luo. High performance control of hydraulic excavator based on fuzzy-PI soft-switch controller. In Proceedings of the IEEE International Conference on Computer Science and Automation Engineering, IEEE, Shanghai, China, pp. 676-679, 2011.

[8] J. Yan, B. Li, Q. Z. Tu, G. Guo, Y. H. Zeng. Automatization of excavator and study of its autocontrol. In Proceedings of the 3rd International Conference on Measuring Technology and Mechatronics Automation, IEEE, Shanghai, China, pp. 604-609, 2011.

[9] M. F. Rahmat, Zulfatman, A. R. Husain, K. Ishaque, Y. M. Sam, R. Ghazali, S. Md Rozali. Modeling and controller design of an industrial hydraulic actuator system in the presence of friction and internal leakage. International Journal of Physical Sciences, vol. 6, no. 4, pp. 3502-3517, 2011.
[10] S. Tafazoli, C. W. De Silva, P. D. Lawrence. Tracking control of an electrohydraulic manipulator in the presence of friction. IEEE Transactions on Control Systems Technology, vol. 6, no. 3, pp. 401-411, 1998.

[11] N. D. Manring. Hydraulic Control Systems, New Jersey: John Wiley \& Sons, 2005.

[12] H. Olsson, K. J. AAstrm, C. Canudas de Wit, M. Gäfvert, P. Lischinsky. Friction models and friction compensation. European Journal of Control, vol.4, no. 3, pp.176-195, 1998.

[13] C. Canudas de Wit, H. Olsson, K. J. Astrom, P. Lischinsky A new model for control of systems with friction. IEEE Transactions on Automatic Control, vol. 40, no. 3, pp.419425, 1995.

[14] J. Wojewoda, A. Stefański, M. Wiercigroch, T. Kapitaniak. Hysteretic effects of dry friction: modelling and experimental studies. Philosophical Transactions of the Royal Society, vol. 366, no. 1866, pp. 747-765, 2008.

[15] B. Eryilmaz, B. H. Wilson. Combining leakage and orifice flows in a hydraulic servovalve model. Journal of Dynamic Systems, Measurement, and Control, vol. 122, no. 3, pp. 576-579, 2000.

[16] K. M. Passino, S. Yurkovich. Fuzzy Control, Menlo Park, CA: Addison Wesley Longman, 1998.

[17] L. Reznik. Fuzzy Controllers, Oxford, Boston: Newnes, 1997.

[18] Y. Shi, R. Eberhart. A modified particle swarm optimizer. In Proceedings of the IEEE International Conference on Evolutionary Computation, IEEE, Piscataway, NJ, USA, pp. 69-73, 1998.

[19] X. S. Yang, Nature-inspired Metaheuristic Algorithms, 2nd ed., United Kingdom: Luniver Press, 2010.

[20] K. Michels, F. Klawonn, R. Kruse, A. Nrnberger. Fuzzy Control: Fundamentals, Stability and Design of Fuzzy Controllers, New York: Springer-Verlag, 2006.

[21] M. Sugeno, T. Taniguchi. On improvement of stability conditions for continuous Mamdani-like fuzzy systems. IEEE Transactions on Systems, Man, and Cybernetics, Part B: Cybernetics, vol. 34, no. 1, pp. 120-131, 2004.

[22] E. G. Tian, C. Peng. Delay-dependent stability analysis and synthesis of uncertain T-S fuzzy systems with time-varying delay. Fuzzy Sets and Systems, vol. 157, no. 4, pp. 544-559, 2006.

[23] J. M. Andújar, J. M. Bravo, A. Peregrín. Stability analysis and synthesis of multivariable fuzzy systems using interval arithmetic. Fuzzy Sets and Systems, vol. 148, no. 3, pp. 337353,2004 .

[24] H. Ying. Structure and stability analysis of general Mamdani fuzzy dynamic models. International Journal of Intelligent Systems, vol. 20, no. 1, pp. 103-125, 2005.

[25] R. E. Precup, M. L. Tomescu, S. Preitl, J. K. Tar, A. S. Paul. Stability analysis approach for fuzzy logic control systems with Mamdani type fuzzy logic controllers. Journal of Control Engineering and Applied Informatics, vol. 9, no. 1, pp. 3-10, 2007. 
[26] L. K. Wong, F. H. F. Leung, P. K. S. Tam. A fuzzy sliding controller for nonlinear systems. IEEE Transactions on Industrial Electronics, vol. 48, no. 1, pp. 32-37, 2001.

[27] L. K. Wong, F. H. F. Leung, P. K. S. Tam. Lyapunovfunction-based design of fuzzy logic controllers and its application on combining controllers. IEEE Transactions on Industrial Electronics, vol. 45, no. 3, pp. 502-509, 1998.

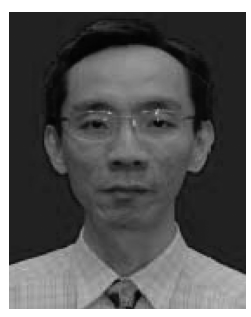

Daniel M. Wonohadidjojo received his B. Eng. degree from Widya Mandala Catholic University, Indonesia in 1991. He obtained his M. Eng. degree from University of Wollongong, Australia in 1995. He has published several papers in journals as well as conference proceedings. Currently, he is undertaking his research in the School of Engineering, Edith Cowan University, Australia.

His research interests include robotics, computational intelligence and control system.

E-mail: dwonohad@our.ecu.edu.au (Corresponding author)

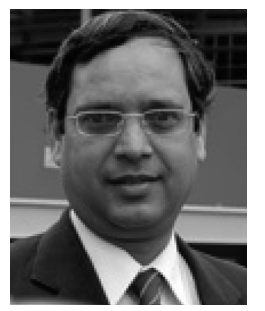

Ganesh Kothapalli received his B. Eng. degree from Bangalore University, India, his M. Sc. degree from University of Alberta, Canada, and his Ph.D. degree from University of New South Wales, Australia. He has been designing microelectronic systems for the past 20 years. He has been teaching electronics, signal processing applications and control engineering at Edith Cowan University since 1996. He held academic positions at University of New South Wales and Monash University prior to joining Edith Cowan University (ECU). From 1991 to 1995, he worked on the applications of artificial neural networks. He was an active member of the Electronic Design Automation Centre and taught courses in the areas of large-scale system simulation using electronic design automation (EDA) tools and circuit design techniques for building robust systems. He has also taught courses covering digital system design using standard cell, gate array and programmable logic arrays. He taught post-graduate courses in mixed analog-digital system design during 2001 at the University of Ulm, Germany while on visiting professorship. He has also published papers on the optimal estimation of parameters and modelling of intelligent systems.

His research interests include control system, electronic, signal processing applications and robotics.

E-mail: g.kothapalli@ecu.edu.cn

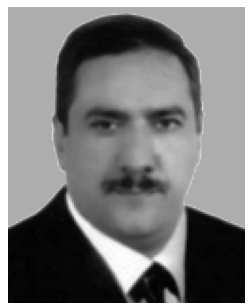

Mohammed Y. Hassan received his B. Sc. degree in electrical and electronics engineering in 1989, M. Sc. degree in control engineering, and received his Ph. D. degree in control engineering and automation from University of Technology, Iraq in 2003. He is an assistant professor and was appointed as a deputy head of Department for Administrative Affairs in the Control and Systems Engineering Department, University of Technology, Iraq in 2012. He taught several courses in the areas of adaptive control, microcontrollers, engineering designs, electrical circuits, electronics, intelligent systems, computer control for undergraduate and postgraduate students. Also, he supervised several master students. He has several research publications in journals and conference proceedings. He has received two endeavour postdoctoral research fellowship awards from the Department of Education, Employments and Workplace Relations (DEEWR) in the government of Australia to do researches in the School of Engineering, Edith Cowan University in 2007 and 2011. He has been appointed as an adjunct academic in Edith Cowan University since 2012.

His research interests include intelligent control, adaptive control, modeling, fuzzy logic, neural network, genetic algorithm, microcomputers and microcontrollers.

E-mail: myhazawy@yahoo.com 